\title{
Optimization of the Atmospheric Pressure Chemical Ionization Liquid Chromatography Mass Spectrometry Interface
}

\author{
D. M. Garcia, S. K. Huang, and W. F. Stansbury \\ Hoechst Celanese Corporation, Corpus Christi Technical Center, Corpus Christi, Texas, USA
}

\begin{abstract}
Use of optimized instrument parameters that result from statistical experimentation revealed that the sensitivity of atmospheric pressure chemical ionization (APCI) liquid chromatography-mass spectrometry (LC/MS) is greater than the sensitivity of an optimized Thermabeam $^{\mathrm{TM}}$ LC/MS interface by about 3 orders of magnitude, when tested on aromatic compounds. APCI is one of the few LC/MS techniques in which the chromatogram is directly comparable with liquid chromatographs that use ultraviolet detection. The optimum instrument parameters for a Finnigan SSQ-7000 APCI LC/MS interface were found at low flow rates (e.g., $0.1 \mathrm{~mL} / \mathrm{min}$ ), relatively low capillary heat (e.g., $225^{\circ} \mathrm{C}$ ), and high sheath-gas pressure (e.g., $60 \mathrm{lb} / \mathrm{in}^{2}$ ). The optimization was achieved by monitoring the responses of sensitivity, fragmentation, and cluster ion formation. The fine tuning for high sensitivity calls for a high percentage of water in the mobile phase. In contrast, a high percentage of organic content in the mobile phase is required to obtain abundant protonated molecular ions with respect to fragmentation and clustering. This is an important consideration for analyses of unknowns. (J Am Soc Mass Spectrom 1996, 7, 59-65)
\end{abstract}

A lthough electrospray ionization (ESI) enjoys several advantages over atmospheric pressure chemical ionization (APCI) in the analysis of thermally labile compounds, APCI appears to be a more versatile liquid chromatography-mass spectrometry (LC/MS) interface than ESI in industrial applications for a wide range of compound mixtures. The potential advantages of APCI over ESI in LC/MS analyses of industrial samples can be summarized as follows.

First, APCI seems to be more compatible with reversed-phase liquid chromatography (LC) than ESI. The separation of components in reversed-phase LC relies on the hydrophobicity of the compounds being separated. Although nearly pure organic solvents sometimes result in optimal ESI sensitivity for certain organic compounds, in a typical gradient elution the longer retention components are less prone to formation of ions in solution. The high specificity of ESI for species that are ionic in solution places a limit on the range of compound types that are amenable to the technique. Certain chemical derivatizations and electrolytic effects [1-8], such as charge transfer complexation and metal ion complexation, were reported to form ionic species for some nonpolar compounds.

Address reprint requests to S. K. Huang, Analytical Department, Hoechst Celanese Corporation, 1901 Clarkwood Road, Corpus Christi, TX 78469.
However, it is difficult to analyze a compound mixture that contains many unknown compound types. Many of the reagents used in these derivatizations are extremely toxic [6] and are not acceptable in industrial laboratories. If ions are not observed, many adjustments, which include the consideration of solution chemistry, are required. These factors made the throughput of LC/MS analyses wane for industrial samples. Peptides and nucleotides are exceptions because they contain both hydrophilic and hydrophobic functional groups.

Second, ESI gives the best result when the LC flow rates are between 2 and $10 \mu \mathrm{L} / \mathrm{min}$. Because many analytical chemists still use conventional columns for United States Pharmacopeia methods and small bore 2-mm-i.d. columns for their method developments, the transfer of their LC methods to the mass spectrometry laboratory is not achieved easily by using ESI as an LC/MS interface. Our experience suggests that the ESI signal is very critical for the length of the capillary tube inside the spray needle. In addition, the ESI signal is not stable when the flow rate is above $0.1 \mathrm{~mL} / \mathrm{min}$, and a column split to get lower flow rates does not solve this problem.

Third, although certain ammonium salts are highly soluble in methylene chloride [9], compounds generally do not form ions in solution for ESI under normal phase high-performance liquid chromatography conditions. Because APCI forms ions in the gas phase, it is not restricted by the conditions employed in these 
chromatographies; ions are always formed for the optimization.

Fourth, because APCI is a gas-phase chemistry, the formation and detection of ions involve little solution chemistry. In contrast, ESI is a solution chemistry [10-13]. An adjustment of conductivity [14] and $\mathrm{pH}$ of the solution, and the employment of appropriate mobile phase and scavenger gas $[15,16]$ are critical to form ions successfully in solution and subsequently transfer ions to the gas phase [10-13, 17]. Finally, ion saturation appears to occur earlier in ESI [11, 13, 17] than in APCI, which limits its use as a process control tool.

APCI utilizes atmospheric pressure ionization (API) technology. An advantage of API technology [18] is little or no memory effect. This is because diffusion of the sample molecules to surrounding surfaces under the ultrasonic nebulization conditions by $\mathrm{N}_{2}$ is much slower at atmospheric pressure than at low pressure in a vacuum. Ions and sample molecules react in the wall-less region that is continuously swept by $\mathrm{N}_{2}$ to exclude molecules that may desorb from the distant walls and sample molecules remain confined within a thin-stream tube. Therefore, API is technically similar to the direct insertion probe, gas chromatography direct coupling, and other discrete-sample inlet systems [19]. This means that analyte molecules are delivered into the mass spectrometry analyzer with no loss of ions due to diffusion or deposition on the walls.

A reaction sequence for an atmospheric ambient air APCI has been studied thoroughly by Huertas and Fontan [20]. In the use of APCI as an LC/MS interface, high pressure $\mathrm{N}_{2}$ gas is employed as a nebulizer, where $\mathrm{N}_{2}^{+}$and $\mathrm{N}_{4}^{+}$ions are formed as primary ions by electron impact of corona-created electrons. Charge exchange reactions of these primary ions with $\mathrm{H}_{2} \mathrm{O}$ from the mobile phase then produce $\mathrm{H}_{3} \mathrm{O}^{+}$and $\mathrm{H}_{3} \mathrm{O}^{+}\left(\mathrm{H}_{2} \mathrm{O}\right)_{n}$ as chemical ionization reagent ions. Direct electron impact of $\mathrm{H}_{2} \mathrm{O}$ and an organic modifier used in the LC (such as $\mathrm{ACN}$ and $\mathrm{MeOH}$ ), followed by subsequent ion-molecule reactions also leads to the formation of $\mathrm{CH}_{3} \mathrm{CN}^{+}\left(\mathrm{CH}_{3} \mathrm{CN}\right)_{n}$ and $\mathrm{CH}_{3} \mathrm{OH}^{+}\left(\mathrm{CH}_{3} \mathrm{OH}\right)_{n}$. The major problem with $\mathrm{APCI}$ is fragmentation and ion clustering (i.e., mass peaks formed with masses heavier than $\left.\left[\mathrm{M}+\mathrm{H}_{3} \mathrm{O}\right]^{+}\right)$that can occur if the parameters involved in both liquid chromatography and mass spectrometry are not tuned properly. For example, an unrecognizable APCI mass spectrum of ibuprofen [MW 206] was obtained (Figure 1a) after the instrument was tuned with 2methoxyethanol as suggested by the manufacturer. Practical application of industrial samples should involve the optimization of the sensitivity of the interface and formation of the protonated molecular ions with respect to fragmentation and ion clustering.

Normally, the optimization procedure involves adjustment of each factor independently and repeatedly until a perceived optimum is reached. As with all optimization schemes, this approach is subject to a

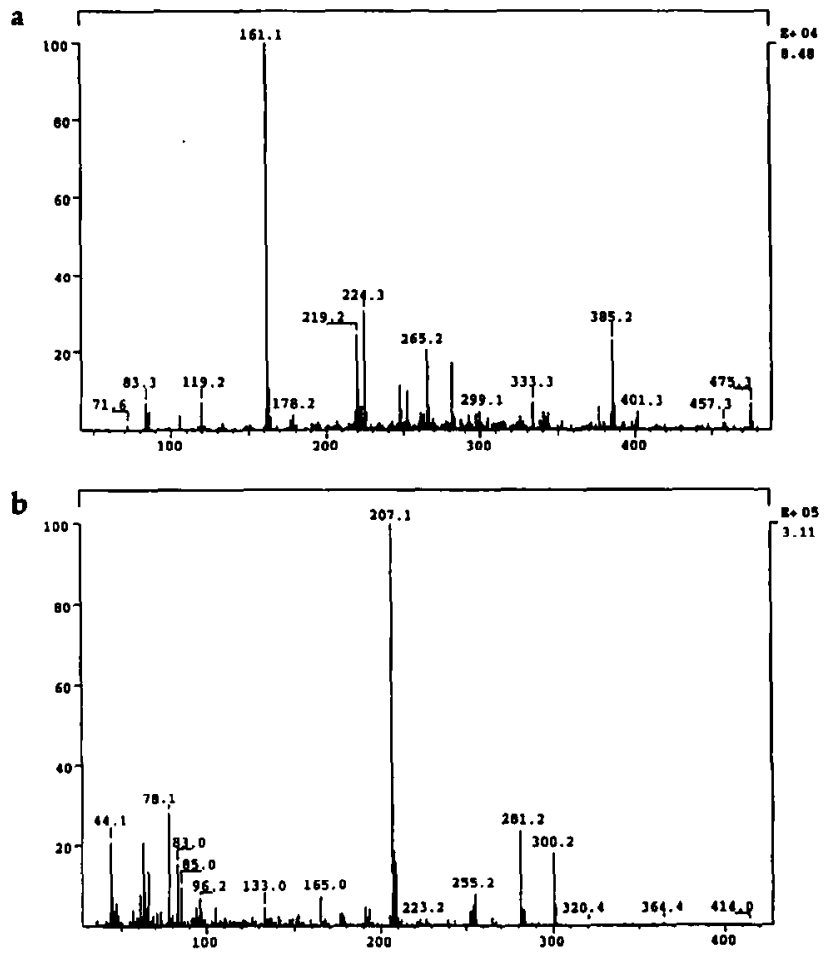

Figure 1. APCI LC/MS of ibuprofen with (a) nonoptimized and (b) optimized interface parameters.

false optimum. One may never reach the true optimum by using the "one variable at a time" approach if the variables interact. There are several methods to optimize a process; they include Simplex algorithms and experimental design [21, 22]. A designed experiment is used to help understand the process and map -through mathematical models-the relationships among the variables within an operating space. Experimental designs, in particular statistical experimental designs, are used to achieve one or several of the following goals:

1. Obtain the desired information by using the least resources (i.e., fewest experimental runs).

2. Screen the important variables out of many possible variables.

3. Take into account the natural variation of the data or experimental errors.

4. Identify the outliers and study their causes.

5. Determine whether the noise is statistically important.

6. Optimize the experimental system.

Statistical experimental designs have been used extensively in the manufacturing industries to optimize the yield, color, hardness, and other desired properties and to minimize the emission of undesired pollutants. Herein, a set of designed experiments was developed to help understand how the APCI LC/MS interface works, to map the relationship among the variables, and finally to determine optimum conditions. Readers 
can familiarize themselves with this methodology from other publications $[23,24]$.

\section{Experimental}

The Finnigan SSQ-7000 APCI LC/MS interface (Finnigan-MAT, San Jose, CA) is shown in Figure 2. Prior to performance of the designed experiments, all of the known variables were considered and evaluated for appropriateness for inclusion in the model. For the sake of simplicity, however, some of the variables that pertain to the interface design characteristics were held constant; these include the pumping capacity and the distance between the emergence of the LC flow and the entrance of the second-stage heated capillary. As a result, only 10 variables were evaluated for their effects on the APCI LC/MS interface system. These variables are mobile-phase composition $\left(5-95 \% \mathrm{H}_{2} \mathrm{O}\right)$, LC flow rate $(0.1-1 \mathrm{~mL} / \mathrm{min}), \mathrm{CH}_{3} \mathrm{COOH}(0-1 \%$ in $\left.\mathrm{H}_{2} \mathrm{O}\right)$, sheath-gas pressure $\left(20-60 \mathrm{lb} / \mathrm{in}^{2}\right)$, auxiliary-gas pressure $\left(20-60 \mathrm{lb} / \mathrm{in}^{2}\right)$, vaporizer temperature $\left(300-500{ }^{\circ} \mathrm{C}\right)$, corona-discharge current $(2.8-6.8 \mathrm{~mA})$, capillary heat $\left(150-300{ }^{\circ} \mathrm{C}\right)$, capillary voltage $(20-100$ $\mathrm{V})$, and tube-lens voltage (20-100 V). Three monitored responses were sensitivity (overall electron multiplier counts), the peak ratio of $\mathrm{MH}^{+}$to total fragment ion currents $\left(\mathrm{MH}^{+} / \sum\right.$ fragm), and the peak ratio of $\mathrm{MH}^{+}$ to total cluster ion currents $\left(\mathrm{MH}^{+} / \Sigma\right.$ cluster).

Tbuprofen (1), which was produced in our production plant (Bishop, TX), was chosen as the model compound for our experimental design throughout this work. As described in the Introduction, an unrecognizable APCI mass spectrum of ibuprofen was obtained when the instrument was tuned with 2methoxyethanol as suggested by the manufacturer. A Waters (Milford, MA) 600-MS liquid chromatograph equipped with a variable UV detector was employed to pump LC effluents into the APCI interface. No signal saturation was observed under designed experimental conditions. The retention time, measured from the onset peak appearance on the UV detector to the peak onset on the mass spectrometer detector, was approximately $20 \mathrm{~s}$ and remained nearly unchanged

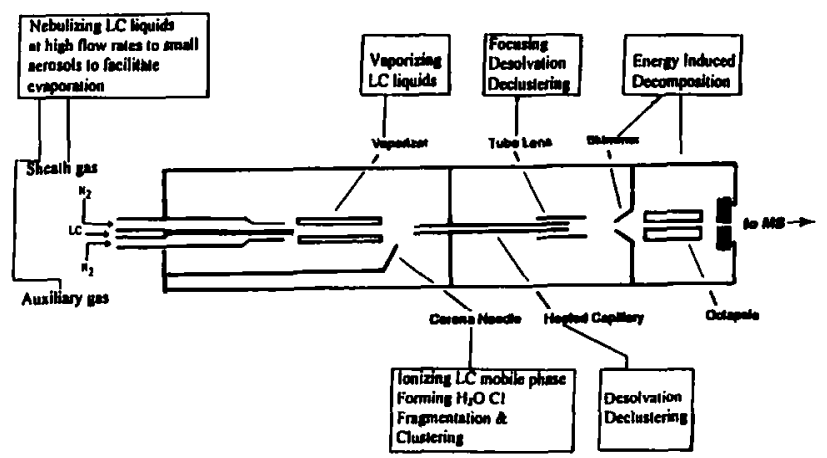

Figure 2. Schematic of the Finnigan SSQ-7000 APCI LC/MS interface.

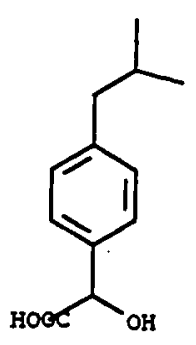

(1)<smiles>CC(=O)c1ccc(O)c(-n2nc3ccccc3n2)c1</smiles>

(2)<smiles>CC(=O)Nc1ccc(O)cc1</smiles>

(3)
Scheme I

under the experimental conditions. The peak width and symmetry registered on the mass spectrometry monitor were nearly identical to those from the UV detector in the optimum region. The sensitivity was measured by integration of the peak area in the reconstructed total ion current (TIC). The $\mathrm{MH}^{+} / \Sigma$ fragm was obtained by taking a ratio of the peak height of the protonated molecular ion of ibuprofen at $\mathrm{m} / \mathrm{z} 207$ to the summation of the peak heights for ions at $m / z<207$. Likewise, the $\mathrm{MH}^{+} / \Sigma$ cluster was obtained by taking a ratio of the peak height of the protonated molecular ion of ibuprofen at $\mathrm{m} / \mathrm{z} 207$ to the summation of the peak heights for ions at $m / z>207$. Peak heights were averaged from several scans across the TIC peak.

The statistical experimental design was generated by using the computer program RS/Discover (BBN Software Products Corporation, Cambridge, MA) run on a VAX 6410 computer (Digital Equipment Corp., Maynard, MA). The data that resulted from the experimental design were analyzed by using the SIMCA statistical package (Umetrics Inc., Boston, MA), which is based on multivariate statistical methods and includes principal components analysis and projection to latent structures $[25,26]$. Because there were 10 variables evaluated for their effects on the APCI LC/MS interface, two phases of experiments were needed. An initial phase involved a screening design to identify the important factors-factors that make a significant change in the response values. The screening design was based on a fractional factorial modeling with center points [21, 22]. The second phase design involved an optimization of these important factors based on a response surface modeling (RSM) [21, 24].

\section{Results and Discussion}

Ten variables described in the experimental section were first evaluated in the screening design, which is based on a fractional factorial modeling, by monitoring sensitivity, $\mathrm{MH}^{+} / \Sigma$ fragm, and $\mathrm{MH}^{+} / \Sigma$ cluster to find the important instrument parameters (variables or factors). In Figure 3, for all the responses, LC flow rate $(-)$ and mobile-phase composition $(-)$ were very strong factors. Tube-lens voltage $(-)$ was also a strong factor for sensitivity, and sheath-gas pressure $(+)$ and 


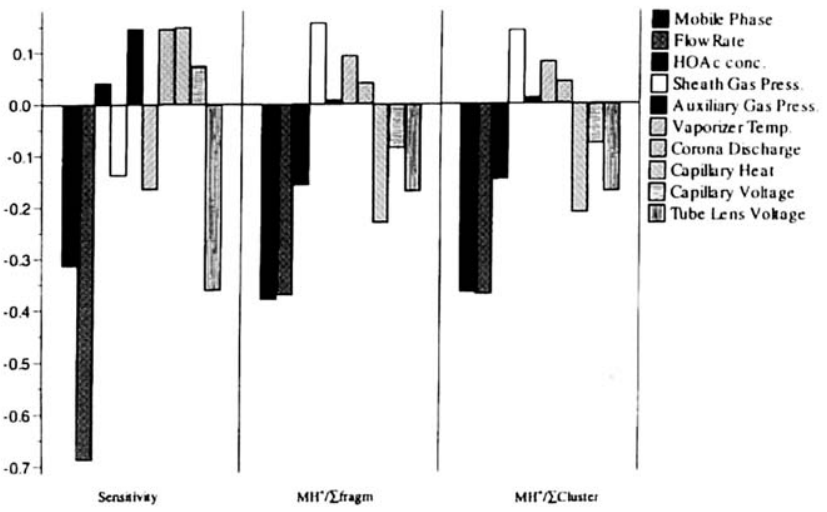

Figure 3. Regression coefficients for all responses for the screening design.

capillary heat $(-)$ were also strong factors for $\mathrm{MH}^{+} / \Sigma$ fragm and $\mathrm{MH}^{+} / \Sigma$ cluster. (The plus and minus signs in parentheses indicates whether the effect was positive or negative on the responses.)

To further optimize these five factors, we generated another experimental design based on a central composite RSM. Therefore, to better define the response surface, a RSM design was developed around the five important factors: LC flow rate, mobile-phase composition, tube-lens voltage, sheath-gas pressure, and capillary heat. The scaled and centered partial least squares regression coefficients for sensitivity, $\mathrm{MH}^{+} / \Sigma$ fragm, and $\mathrm{MH}^{+} / \Sigma$ cluster models are given in Table 1 . The integrity of the models was evaluated by a measure of how well the model fit the data $\left(R^{2}\right)$ and a measure of how valuable the model was for predictions $\left(Q^{2}\right)$. The closer $R^{2}$ and $Q^{2}$ are to 100 , the better is the model. In general, a good model is suggested when $R^{2}$ and $Q^{2}$ are each greater than 60. A lower value of $Q^{2}(36)$ in $\mathrm{MH}^{+} / \Sigma$ fragm indicates a natural variation of data in the measurement.

The LC flow rate had a profound negative effect on the sensitivity, $\mathrm{MH}^{+} / \Sigma$ fragm, and $\mathrm{MH}^{+} / \Sigma$ cluster. The effect of mobile-phase composition is positive on the sensitivity, but is negative on the $\mathrm{MH}^{+} / \sum$ fragm and $\mathrm{MH}^{+} / \Sigma$ cluster. The mobile-phase composition has a more important negative effect on $\mathrm{MH}^{+} / \Sigma$ cluster and $\mathrm{MH}^{+} / \sum$ fragm than its positive effect on the sensitivity according to Table 1. Sheath-gas pressure has a strong positive effect on all three response factors.

The study of various contour plots under different conditions lead to optimized parameters for all three
Table 1. Regression coefficients obtained from fitting a quadratic model to each of the response variables, the percentages of total variance accounted for by the models $\left(R^{2}\right)$, and the value of the models for predictions $\left(Q^{2}\right)$

\begin{tabular}{|c|c|c|c|}
\hline Term & Sensitivity & $\begin{array}{c}\mathrm{MH}^{+} / \\
\sum \text { fragm }\end{array}$ & $\begin{array}{c}\mathrm{MH}^{+} / \\
\text {Ecluster }\end{array}$ \\
\hline Constant & 1.0897 & -1.3849 & -2.4941 \\
\hline Mobile phase $\left(X_{1}\right)$ & 0.0976 & -0.1278 & -0.2414 \\
\hline LC flow rate $\left(x_{2}\right)$ & -0.3767 & -0.3043 & -0.2479 \\
\hline $\begin{array}{l}\text { Sheath-gas pressure } \\
\left(x_{3}\right)\end{array}$ & 0.2915 & 0.3128 & 0.2207 \\
\hline Capillary heat $\left(X_{4}\right)$ & 0.2596 & -0.2552 & -0.1831 \\
\hline $\begin{array}{l}\text { Tube-lens voltage } \\
\left(x_{5}\right)\end{array}$ & 0.0435 & -0.0883 & 0.1176 \\
\hline$x_{1}^{2}$ & -0.0226 & -0.0019 & 0.0543 \\
\hline$x_{2}^{2}$ & -0.0187 & -0.1378 & -0.1976 \\
\hline$x_{3}^{2}$ & -0.0801 & -0.0274 & -0.0440 \\
\hline$x_{4}^{2}$ & -0.0512 & -0.2219 & -0.4177 \\
\hline$x_{5}^{2}$ & -0.0825 & -0.2091 & -0.2947 \\
\hline$x_{1}^{*} x_{2}$ & 0.1774 & -0.0151 & 0.1579 \\
\hline$x_{1}^{*} x_{3}$ & 0.2364 & -0.2107 & -0.1902 \\
\hline$x_{1}^{*} X_{4}$ & 0.0074 & 0.1892 & 0.0078 \\
\hline$x_{i}^{*} x_{5}$ & 0.0557 & -0.1169 & 0.0437 \\
\hline$x_{2}^{*} x_{3}$ & -0.1215 & -0.1656 & -0.0718 \\
\hline$x_{2}^{*} x_{4}$ & 0.1268 & 0.0122 & 0.1148 \\
\hline$x_{2}^{*} X_{5}$ & 0.0096 & 0.4277 & 0.1624 \\
\hline$x_{3}^{*} x_{4}$ & -0.2750 & 0.0011 & -0.0601 \\
\hline$x_{3}^{*} x_{5}$ & -0.2222 & -0.1117 & -0.0118 \\
\hline$X_{4}^{*} X_{5}$ & -0.4378 & -0.0787 & -0.0137 \\
\hline$R^{2}$ & 93 & 86 & 87 \\
\hline$Q^{2}$ & 64 & 36 & 58 \\
\hline
\end{tabular}

Note: $X$, are linear terms, $X_{i}^{2}$ are quadratic terms, and $X_{i}^{*} X$, are interaction terms. The regression coefficients from these terms are of particular interest to the chemist, especially if their interaction is of significance within the model.

responses (Table 2), when the LC flow rate and sheathgas pressure were set at $0.1 \mathrm{~mL} / \mathrm{min}$ and $60 \mathrm{lb} / \mathrm{in}^{2}$, respectively. It is clear that both the sensitivity and $\mathrm{MH}^{+} / \sum$ fragm are optimized at low tube-lens voltages $(\sim 30 \mathrm{~V})$, whereas the $\mathrm{MH}^{+} /$¿cluster is optimized at higher tube-lens voltages $(\sim 60 \mathrm{~V})$. Similarly, all three responses are optimized at different capillary heat values in all ranges of mobile-phase composition. An arbitrary $225^{\circ} \mathrm{C}$ appears to be a good compromise for the capillary heat temperature. A compromise needs to be made for both tube-lens voltage and capillary heat

Table 2. Optimized parameters for sensitivity, $\mathrm{MH}^{+} / \Sigma \mathrm{fragm}$, and $\mathrm{MH}^{+} / \Sigma$ cluster under different gradient conditions; the LC flow rate and sheath-gas pressure were set at $0.1 \mathrm{~mL} / \mathrm{min}$ and $60 \mathrm{lb} / \mathrm{in}^{2}$, respectively

\begin{tabular}{llll}
\hline Mobile phase & \multicolumn{1}{c}{ Sensitivity } & \multicolumn{1}{c}{$\mathrm{MH}^{+} / \Sigma$ fragm } & \multicolumn{1}{c}{$\mathrm{MH}^{+} / \Sigma \mathrm{cluster}$} \\
\hline \hline $5 \% \mathrm{H}_{2} \mathrm{O}$ & Tube-lens voltage $=20 \sim 40 \mathrm{~V}$ & Tube-lens voltage $=30 \sim 40 \mathrm{~V}$ & Tube-lens voltage $=50 \sim 60 \mathrm{~V}$ \\
& Capillary heat $=280 \sim 300^{\circ} \mathrm{C}$ & Capillary heat $-160 \sim 190^{\circ} \mathrm{C}$ & Capillary heat $=200 \sim 230{ }^{\circ} \mathrm{C}$ \\
$50 \% \mathrm{H}_{2} \mathrm{O}$ & Tube-lens voltage $=20 \sim 40 \mathrm{~V}$ & Tube-lens voltage $=20 \sim 35 \mathrm{~V}$ & Tube-lens voltage $=55 \sim 65 \mathrm{~V}$ \\
& Capillary heat $=280 \sim 300^{\circ} \mathrm{C}$ & Capillary heat $=190 \sim 210^{\circ} \mathrm{C}$ & Capillary heat $=210 \sim 220{ }^{\circ} \mathrm{C}$ \\
$95 \% \mathrm{H}_{2} \mathrm{O}$ & Tube-lens voltage $=20 \sim 30 \mathrm{~V}$ & Tube-lens voltage $=20 \sim 30 \mathrm{~V}$ & Tube-lens voltage $=50 \sim 70 \mathrm{~V}$ \\
& Capillary heat $=280 \sim 300^{\circ} \mathrm{C}$ & Capillary heat $=200 \sim 240^{\circ} \mathrm{C}$ & Capillary heat $=195 \sim 225{ }^{\circ} \mathrm{C}$ \\
\hline
\end{tabular}


to optimize all three responses in the gradient elution from 95 to $5 \% \mathrm{H}_{2} \mathrm{O}$.

As shown in Figure 4, when the tube-lens voltage is set at $55 \mathrm{~V}$, the sensitivity is optimized at $60-\mathrm{lb} / \mathrm{in}^{2}$ sheath-gas pressure. The sensitivity decreases by a factor of 2 when the mobile phase is changed from 95 to $5 \% \mathrm{H}_{2} \mathrm{O}$ at $60-\mathrm{lb} / \mathrm{in}^{2}$ sheath-gas pressure, yet the values of $\mathrm{MH}^{+} / \sum$ fragm and $\mathrm{MH}^{+} / \sum$ cluster increase by factors of 5 and 10, respectively. On the other hand, when the tube-lens voltage is set at $20 \mathrm{~V}$, the sensitivity is still optimized at $60-\mathrm{lb} / \mathrm{in}^{2}$ sheath-gas pressure and high percentage of $\mathrm{H}_{2} \mathrm{O}$. A gradient elution from 95 to $5 \% \mathrm{H}_{2} \mathrm{O}$ results in a sensitivity loss by a factor of 2. In the meantime, both $\mathrm{MH}^{+} / \sum$ fragm and $\mathrm{MH}^{+} /$ Ecluster increase by factors of 3 and 10 , respectively, when the mobile phase is scanned from 95 to $5 \% \mathrm{H}_{2} \mathrm{O}$ (not shown).

a

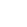

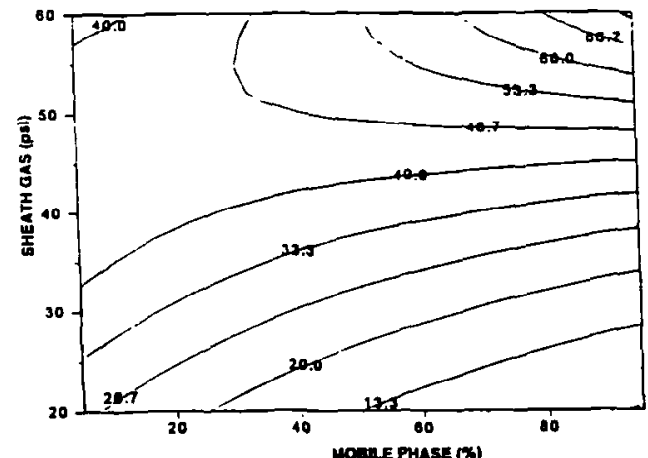

b

MH'/rfragm

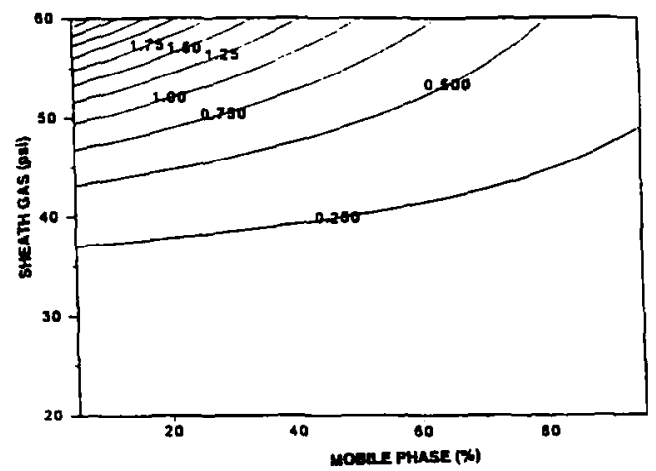

c

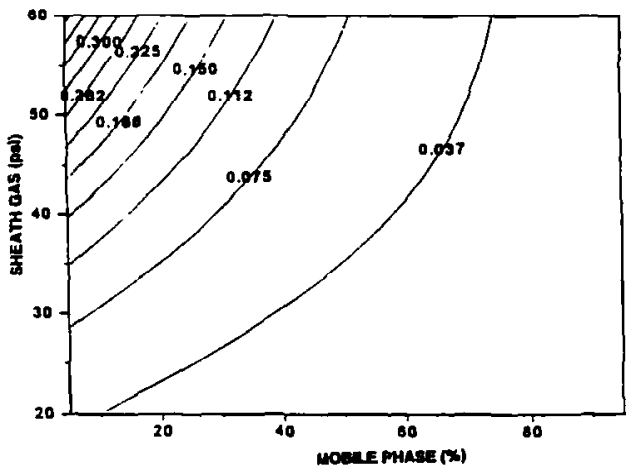

Figure 4. Contour plots of (a) sensitivity, (b) $\mathrm{MH}^{+} / \sum$ fragm, and (c) $\mathrm{MH}^{+} / \Sigma$ cluster as a function of mobile phase $\left(\% \mathrm{H}_{2} \mathrm{O}\right)$ and sheath-gas pressure. The LC flow rate, capillary heat, and tube-lens voltage were set at $0.1 \mathrm{~mL} / \mathrm{min}, 225{ }^{\circ} \mathrm{C}$, and $55 \mathrm{~V}$, respectively, for these plots.
From the preceding studies, we make the following conclusions:

1. The performance of the Finnigan SSQ-7000 APCILC/MS interface is optimized at $0.1-\mathrm{mL} / \mathrm{min} \mathrm{LC}$ flow rate, $60-\mathrm{lb} / \mathrm{in}^{2}$ sheath-gas pressure, $225^{\circ} \mathrm{C}$ capillary heat, and $55 \mathrm{~V}$ of tube-lens voltage. In our corporation these optimized parameters have been applied successfully to ibuprofen (Figure 1b) and over 40 chemical and drug analyses with their associated trace impurities. The sensitivity of our APCI LC/MS interface with the described optimized parameters was found to be 500-1000 times higher than that of an optimized Thermabeam ${ }^{\mathrm{TM}}$ LC/MS technique for most of the aromatic compounds analyzed in our laboratory. Figure 5 shows a LC/UV

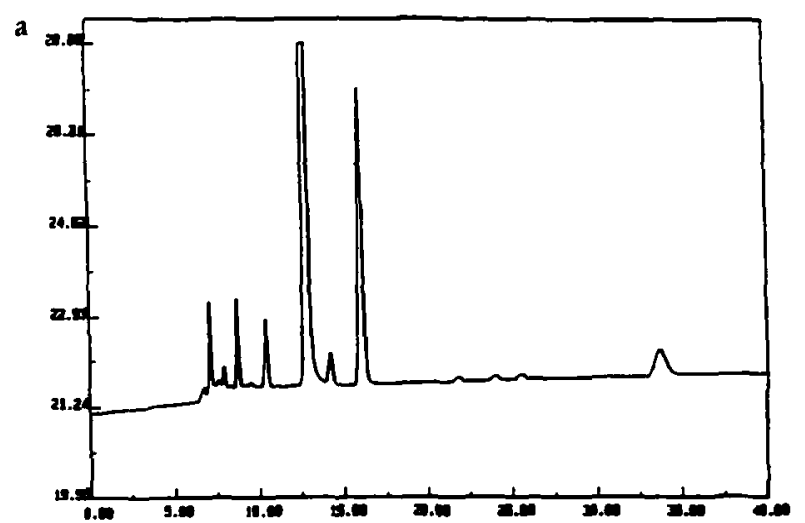

b
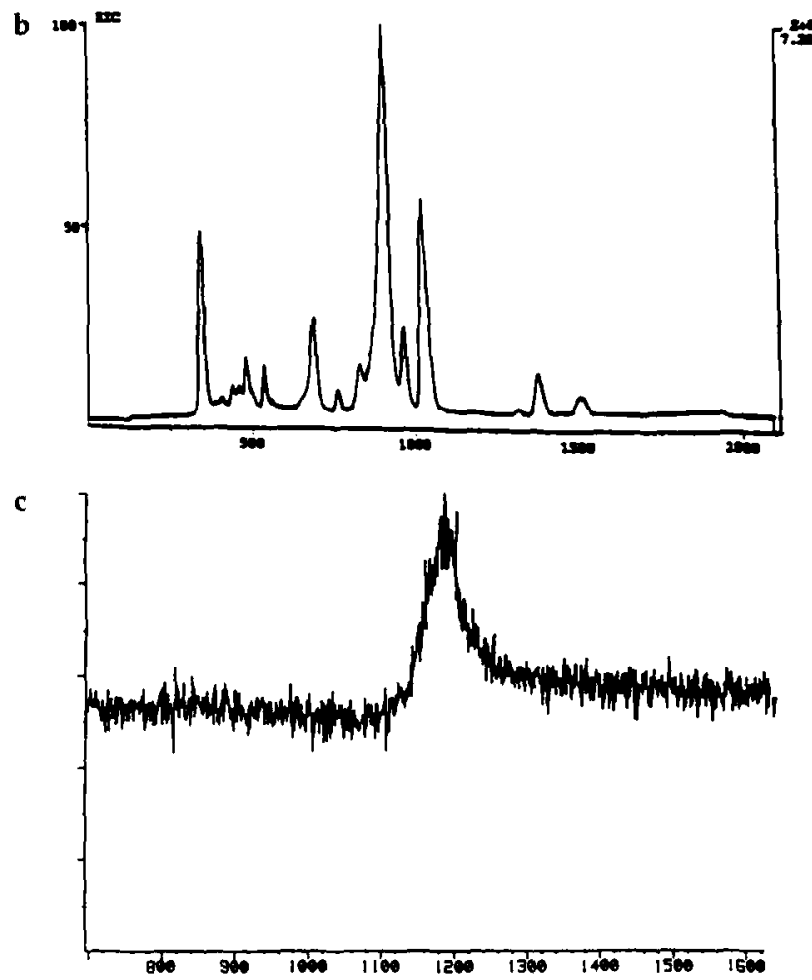

Figure 5. Comparison of (a) LC/UV, (b) APCI LC/MS, and (c) Thermabeam LC/MS analysis of a reaction mixture of 2(2'-hydroxy-5'-acetylphenyl)-benzotriazole. The injection amounts were $0.5,1.5$, and $3.5 \mu \mathrm{g}$, respectively. 
analysis, a reconstructed total ion chromatogram (TIC) of APCI LC/MS, and a Thermabeam LC/MS for the same reaction mixture of 2(2'-hydroxy-5'acetylphenyl)-benzotriazole (2). In this particular instance, the APCI LC/MS interface was found to be about 1000 times more sensitive than the Thermabeam LC/MS interface.

2. It is possible that the optimized parameters are compound dependent. It was observed that acetaminophen or 4-hydroxy- $N$-acetyl aniline (3) had a much wider optimal region than ibuprofen. Furthermore, a few chemicals or drugs such as ritodrine hydrochloride did not yield an intense $[\mathrm{M}+\mathrm{H}]^{+}$with the described optimal parameters. However, a small adjustment of the vaporizer temperature, capillary heat, and tube-lens voltages generally led to formation of an intense $[\mathrm{M}+\mathrm{H}]^{+}$. In these instances, a change of important variables such as the LC flow rate, mobile-phase composition, and sheath-gas pressure away from the optimal values correlates with the decrease of all three responses. It is therefore reasonable to conclude that ibuprofen appears to model the variables in the APCI LC/MS interface very well for the similar-class compounds (e.g., mostly aromatic compounds). The performance difference observed for ritodrine hydrochloride appears to be associated with its volatility and thermal lability, which were not factors considered in this article. Fortunately, although these two factors are compound dependent, they appear to be independent of other factors. Consequently, abundant $\mathrm{MH}^{+}$ions with respect to $\mathrm{MH}^{+} / \Sigma$ fragm and $\mathrm{MH}^{+} / \Sigma$ cluster can be produced by simple adjustment of the vaporizer temperature, capillary heat, and the tube-lens voltage for compounds that fail to yield abundant $\mathrm{MH}^{+}$ions by the optimized parameters described herein.

3. Optimization of both $\mathrm{MH}^{+} / \Sigma$ fragm and $\mathrm{MH}^{+} /$ Ecluster is more important than maximization of the sensitivity for unknowns.

4. Because both $\mathrm{MH}^{+} / \Sigma$ fragm and $\mathrm{MH}^{+} / \Sigma$ cluster optimize at low percentage $\mathrm{H}_{2} \mathrm{O}$, appropriate amounts of organic solvent may be added postcolumn to optimize the $\mathrm{MH}^{+}$formation.

5. It is possible that the APCI interface will improve further at even lower LC flow rate according to the current experimental design study. Practical considerations should include method development on narrow-bore LC columns with inner diameters less than $1 \mathrm{~mm}$ and an LC pump that is capable of pumping reliably at the low LC flow rate.

\section{Conclusion}

APCI and ESI are complementary ionization techniques for LC/MS. Both ionization techniques together allow the analysis of most chemical classes, as illustrated in Figure 6. Our experience in LC/MS analyses

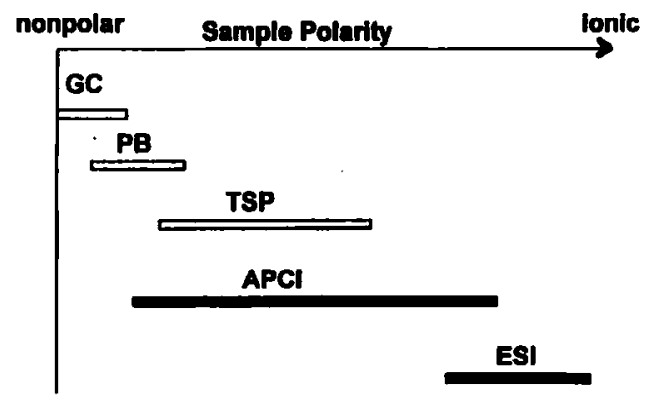

Figure 6. The relationship between the sample polarity and the hyphenated chromatography-mass spectrometry ionizationdesorption techniques.

of industrial samples suggests that APCI gives the best sensitivity for molecules that have relatively low to moderately high polarity, yet ESI yields the best sensitivity for ionic species and rhodium catalysts (Huang, S. K.; Garcia, D. M., unpublished results). The practical advantages of APCI LC/MS over ESI LC/MS for small molecules, that is, MW $<1500 \mathrm{u}$, include accommodation of high LC flow rates and different LC types, less concern about formation of ions in solution, and ability to analyze samples with a wider concentration range.

The optimized parameters described in this article are important for real-world analyses of industrial unknowns and trace impurities without resorting to tedious enrichment and isolation of trace unknowns for their structural determinations by other analytical techniques. For an unknown analysis, an unambiguous assignment of the molecular ion is a very important task. The optimized parameters described here allow formation of protonated molecular ions for most of the unknowns analyzed in our laboratory without the complication of formation of intense fragments and clusters. The sensitivity of our APCI LC/MS interface with the optimized parameters described herein was found to be 500-1000 times higher than of a Thermabeam LC/MS technique [24] for most of the aromatic compounds analyzed in our laboratory. We recently used these optimized parameters to characterize a mixture that contained oligomers of acrylic acid and its butyl acrylates with the method transferred from the plant (Huang, S. K.; Garcia, D. M., unpublished results). Surprisingly, the use of other parameter values resulted in hard-to-interpret mass spectra. This is also one of the few LC/MS techniques that is directly comparable with LC/UV. In some cases, APCI LC/MS has even higher sensitivity than LC/UV. In addition, application of a potential difference across the skimmer and octapole (Figure 2) enables APCI to yield structural information, whereas UV cannot.

\section{Acknowledgment}

The encouragement of Hoechst Celanese management to publish this article and their critical review of this paper are greatly appreciated. 


\section{References}

1. Van Berkel, G. J.; McLuckey, S. A.; Glish, G. L. Anal. Chem. 1991, 63, 2064.

2. Quirke, J. M. E.; Adams, C. L.; Van Berkel, G. J. Anal Chem. 1994, 66, 1302.

3. Colton, R.; Traeger, J. C.; Harrey, J. Org. Mass Spectrom. 1992, 27, 1030.

4. Hiroka, K.; Kudaka, I.; Fujimaki, S.; Shinohara, H. Rapid Conmun. Mass Spectrom. 1992, 6, 254.

5. Wilson, S. R.; Wu, Y. J. Am. Soc. Mass Spectrom. 1993, 4, 596.

6. Van Berkel, G. J.; Asano, K. G. Anal. Chem. 1994, 66, 2096.

7. Van Berkel, G. J.; Asano, K. G.; McLuckey, S. A. I. Am. Soc. Mass Spectrom. 1994, 5, 689.

8. Van Berkel, G. J.; McLuckey, S. A.; Glish, G. L. Anal. Chem. 1992, 64, 1586.

9. Zook, D. R.; Bruins, A. P. Proceedings of the 42nd ASMS Conference on Mass Spectrometry and Allied Topics; Chicago, IL, 1994.

10. Blades, A. T.; Ikonomou, M. G.; Kebarle, P. Anal. Chem. 1991, $63,2109$.

11. Ikonomou, M. G.; Blades, A. T.; Kebarle, P. Anal. Chem. 1991, 63, 1989.
12. Fenn, J. B.; Mann, M.; Meng, C. K.; Wong, S. F. Mass Spectrom. Rev. 1990, 9, 37.

13. Fenn, J. B. J. Am. Soc. Mass Spectrom. 1993, 4, 524.

14. Tang, L.; Kebarle, P. Anal. Chem. 1991, 63, 2709.

15. Straub, R. F.; Voyksner, R. D. I. Am. Soc. Mass Spectrom. 1993, 4, 578 .

16. Cole, R. B.; Harrata,A. K. J. Am. Soc. Mass Spectrom. 1993, 4, 546.

17. Kebarle, P.; Tang, L. Anal. Chem. 1993, 65, 972A.

18. Buckley, J. A.; French, J. B.; Reid, N. M. Can. Aeronaut. Space J. 1974, 20, 231.

19. The API Book; PE Sciex: Thornhill, ON, Canada, 1990.

20. Huertas, M. L.; Fontan, J. Atmospheric Environ. 1975, 9, 1018.

21. Box, G. E. P.; Hunter, W. G.; Hunter, S. J. Statistics for Experimenters; Wiley: New York, 1978.

22. Montgomery, D.C. Design and Analysis of Experiments; Wiley: New York, 1991.

23. Mark, H.; Workman, J., Jr. Spectroscopy 1994, 9, 26-27, 30-32; 10, 17-20.

24. Huang, S. K.; Glancy, S. B.; Stanbury, W. F. Rapid Commun. Mass Spectrom. 1993, 7, 722; Huang, S. K.; Garza, N. J. Am. Soc. Mass Spectrom. 1995, 6, 507.

25. Martens, H.; Naes, T. Multivariate Calibration; Wiley: New York, 1989.

26. Wold, S. Chemometrics and Intelligent Lab. Syst. 1987, 2, 37. 